\title{
Tropical Knowledge: Archipelago Consciousness and the Governance of Excess
}

\author{
Paul Carter
}

RMIT University

\begin{abstract}
The focus of this address is on the potential of tropical geographies to inform and transform western epistemologies. The Humboldt brothers establish an identification of the tropics with (simultaneously) the origin of evolutionary development and its finest, most diversified realisation. In contrast, an imperial overlay of continentally imagined national territories has, particularly in the Indonesian, Malaysian and Philippine archipelago, imposed a counter-narrative of truncated regional development and exacerbated social disenfranchisement. This paper looks at the scope to reconfigure ocean connections between formerly connected tropical communities. It suggests that such a project does not drive towards a unitary outcome (a new raft of international legislation, for example) but towards a radically different model of coexistence. In this the performance of sociability is indistinguishable from the protocols governing travel. The emergence of 'archipelago consciousness' has, it is proposed, direct implications for the formation of creative communities able to cooperate because of their commitment to managing complexity in concrete situations. The communication thus evolved is, like the navigation of the archipelago, dialogical, poetically mediated and fluid.
\end{abstract}

F or some time rumours of 'the oldest pyramid on the planet' have been coming out of Java. Supported by Indonesia's President Susilo Bambang Yudhoyono, geologist Danny Hilman is attempting to prove that it is buried under the megalithic site of Gunung Padang: 'If he is correct the find would rewrite prehistory in the same way as the discovery of a minihuman "hobbit" on the eastern Indonesian island of Flores rewrote paleoanthropology., Finding the pyramid and proving its antiquity would, says the Coordinator of the Independent Team overseeing the 2013 archaeological investigations, show that Indonesia 'as [an] archipelago nation has [a] civilization as advanced as the Egyptian civilization [and] much older.' The Coordinator works under the direction of the President, his independence needs to be taken with a grain of salt; and the phrase 'archipelago nation' is likewise code for a new nation state in search of an identity. What could better meet this need than a grand foundational myth? To discover that Java had been host to 'the golden age' and was indeed 'the cradle of civilisation' would be to make it a geographical metonym for an Indonesia that was at once original and unique, both progenitor and outside all other genealogies. A perceived geo-political weakness - Indonesia's non-continental, archipelagic character - is turned into strength, as its abundance and variety of islands are shown to cultivate a diversity of radical and original evolutionary possibilities impossible in less individuated homogeneous environments.

But suppose that, instead of stretching the envelope of the nation state to an extreme in order to incorporate an archipelagic region, we entertained the possibility that the scatter of the archipelago, its nebulous distribution across a region of waters, had a logic of its own. The poet and political utopianist Percy Bysshe Shelley would have understood this: to incarnate his ideal state of social emancipation and human freedom, he thought of sailing to The

\footnotetext{
${ }^{1}$ Michael Bachelard, The Age, 27 July 2013.
} 
Sporades, a group of islands in the Aegean Sea which, as their name implied, constituted an extreme archipelagic condition; in relation to the rationally organized Cyclades, the occasional distribution of these islands defied conventions of predictability, regularity and subordination to a geometrical rule. The great theorist of languages Wilhelm von Humboldt did not share Shelley's revolutionary parti pris - he broadly accepted 'the national character of languages, 2 - yet he had no doubt that searches for the 'so-called cradle of the human race' had a 'mythical character': we do not know, he says, of any time 'in which the human race has not been divided into social groups. ${ }^{, 3}$ In other words language was inherently plural. Even the origins of different languages obeyed this rule. Superficially, Wilhelm's unfinished treatise on Kawi, the ancient language of Java, could be seen as offering early support for the Indonesian nationalist attempt to prove the nation's predestination. In fact, though, von Humboldt attributes the genius of Kawi to the archipelagic character of communication in the region where it developed - a point to be touched on later

Of course archipelagic communication is not necessarily emancipatory: the challenge of physical separation and multiplicity might have the opposite effect. Just as languages lose their poetic charge when globalised, so the discourse of the archipelago might have to be artificially unified and differentiated from discourse at large. Cribb and Ford explain how the archipelago can be used 'to highlight the way in which dispersed institutions are able to have an identity because the physical distance that separates them is trumped by the social distance that detaches them from their immediate environment but unites them with each other.' They cite Solzhenitsyn's Gulag Archipelago where 'islands of incarceration shared a way of life and complex social network in which people, goods and information were exchanged, but as islands they were detached from the society around them. ${ }^{4}$ Contrast this constellated island metaphor with the anti-centralist 'archipelagic confederation' promoted by Filipino anarchist writer, Bas Umali: 'a structure that connects and interlinks politically an economically every community in the archipelago, without the need for a centralised state. It would consist of networks of autonomous villages (barangays), together comprising regional assemblies in which translocal coordination could take place. These regional assemblies in turn would constitute an archipelago wide assembly.

Cuevas-Hewitt argues that a distinctively archipelagic political organization, a 'territory without terrain', depends on evaluating 'the sea between - the site of multiple relationships that are never fixed, but constantly in flux. ${ }^{, 6}$ The antithesis of this is, he considers, an obsession with islands. The 'nation-state-centric view of the world' imagines it as 'composed of discrete, bounded entities': 'it sees only islands of order, forgetting that there is a whole ocean out there that mixes the things of the world.' And Cuevas-Hewitt makes the nice point that this ""nesological" worldview' imposes 'a stark geometry of inside and outside upon thought. ${ }^{7}$ But perhaps the antithesis of the archipelago is not the island but the continent. The Gulag or nation-centric conception of the archipelago is one that aims to consolidate all the parts into a single solid mass: as far as possible it tries to eliminate the scope for selforganisation associated with the sea between. In the continentalist conception of the nation

\footnotetext{
${ }^{2}$ Humboldt, Cosmos, vol 1, 357

${ }^{3}$ Ibid, 354-355

${ }^{4}$ Robert B. Cribb, Michel Ford (et al, eds), Indonesia: Beyond the Water's Edge: Managing an Archipelagic State, 7.

${ }^{5}$ Marco Cuevas-Hewitt, 'Sketching Towards an Archipelagic Poetics of Postcolonial Belonging, Budhi 1, 2007, $239-246,242-3$

6 Ibid, 244.

7 Ibid, 241
} 
state, consolidation into a single mass trumps distance. In this case it is important to avoid the stark geometry of continentalist thinking in characterising the archipelago. For instance, in the archipelago terms like 'island' and 'ocean' may change their meaning. As an alternative way of organizing communication, the archipelago may consist entirely of ports of call: no island is isolated and, if it is, it forms no part of the archipelago. Similarly, as a fractal figure, composed of regions within regions, seas within seas, the archipelago had neither limit nor outside. In this case there is in the archipelago no such thing as a girdling ocean: the archipelago is not contained but contains itself.

As this implies it is not only the theory of communication that changes in the archipelago but its practice. The archipelago may have a unity but it is one that cannot be fully represented: it cannot be conceptualized from the outside but must instead be explored and narrated like a labyrinth. As the complexity of it exceeds reduction to fixed rules, other means must be used to evoke its organization. Poetic figures of speech - the metaphor that draws distant things

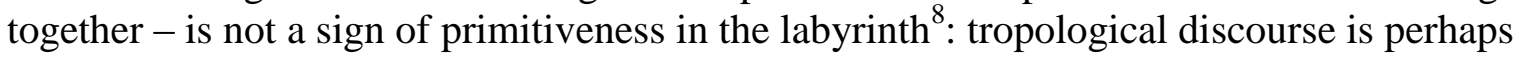
inherent in the description of what exceeds rational representation. Nor is this tension between unity and diversity confined to the operations of language: it has an impact on scientific method. Alexander von Humboldt called his encyclopedic treatise on physical geography Cosmos, offering as his first definition of that word 'the order or adornment of discourse.' ${ }^{9}$ In order for a physical description of the universe to be feasible its parts must be brought together (discourse has the etymological sense of a running hither and thither); but prior to this they must be differentiated or regionalized. The discourse that does this cannot simply be an 'aggregation' of facts; it must acknowledge the distribution of 'organic types' and show the 'connecting links. ${ }^{10}$ More exactly, if comparable climatic zones around the globe display comparable ecologies (as we would say), the physical description of the globe needs to demonstrate a 'principle of unity and a primitive plan of distribution revealed in the multiplicity of the distinct organisations by which these regions are occupied. ${ }^{11}$

The principle of unity may drive the enterprise but von Humboldt repeatedly compares his quest to that of a traveller setting out from land into an unknown ocean: it is perhaps 'the impression of boundlessness and immeasurability, which are presented to the mind by every sea voyage, ${ }^{12}$ that stimulates the intellect to 'discover the empire of certain natural laws, grand and simple as nature itself.' In meeting this ambition, though, von Humboldt emphasizes that there must be conceptual stepping stones. The 'immeasurable riches' of nature can only be approached 'by distributing them into groups. ${ }^{, 13}$ The groups are physical (climatic and physical regions) but they are also intellectual (reflected in the different experimental sciences). 'Unity of contemplation' ${ }^{14}$ transcends 'conceptions of the universe based upon reason. ${ }^{15}$ In fact, to proceed by speculative reason alone is to risk the kind of step-by-step logic that ignores at its peril 'the complication of phenomena. ${ }^{16}$ It is 'nesological' in Cuevas-Hewitt's sense, isolated from the real world of passage and growth as von Humboldt says, 'by persisting in the pursuit of laws, we may find our course suddenly

\footnotetext{
${ }^{8} \mathrm{Ibid}, 41:$ 'the presentiment of discovery, the vague intuition of the mysterious to be unfolded, and the multiplicity of the paths before us, all tend to stimulate the exercise of thought in every stage of knowledge.'

${ }^{9}$ Cosmos, 69

${ }^{10}$ lbid, 55 .

${ }^{11}$ lbid, 62

12 Ibid, 310; see also 50.

${ }^{13}$ Ibid, 73

${ }^{14}$ Ibid, 162

${ }^{15}$ Ibid, 77

${ }^{16}$ Ibid, 75
} 
arrested by an impassable chasm.' ${ }^{, 17}$ 'Science does not present itself to man until mind conquers matter in striving to subject the result of experimental investigation to rational combinations. ${ }^{, 18}$ In other words the detour through matter is not a deferral of arriving at a Platonic plan: it is the mirror of reason, understood not as a state but as a dynamic process involving speculation, imagination, inductive and deductive logic. The combinatory mind exists through and in relation to the outside world. We know the world because it is like us: 'the external world has no real existence for us beyond the image reflected within ourselves through the medium of the senses. ${ }^{19}$ The world, indeed the universe, becomes a cosmos when what the senses tell us is translated into 'discourse': reason its ornament.

Von Humboldt's theory of knowledge is archipelagic. Unity is understood as the discovery of 'connecting links' between 'groups' or 'regions' of phenomena. Even if these links could be reduced to a precursor of Einstein's notion of a unified field theory, they would not be rendered obsolete, as the force that connected them would also be the force that their separation produced. To this extent, von Humboldt recognized organizational parallels between heaven and earth, remarking, 'If we compare the regions of the universe with one of the island-studded seas of our own planet, we may imagine matter to be distributed in groups, ether as unresolvable nebulae of different ages ... or as already agglomerated into clusters of stars, or isolated spheroidal bodies. ${ }^{20}$ In space 'We see matter either agglomerated into rotating, revolving spheres of different density and size, or scattered though space in the form of self-luminous vapour. ${ }^{21}$ While he is discreet in drawing parallels between celestial and terrestrial groupings of matter or energy forms, noting simply that some philosophers see an analogy between 'the genetic evolution' of the stars and the various stages of growth of 'organic phenomena', ${ }^{22}$ it is clear that von Humboldt sees the sky-earth analogy as more than ornamental. By uniting 'the phenomena of our own globe and those presented in the regions of space ... [we] convert the physical history of the globe into the physical history, the one term being modeled upon that of the other. ${ }^{23}$ In other words, any knowledge will be discursive, a running hither and thither between analogous regions with the object of showing 'the simultaneous action and connecting links of the forces which pervade the universe. ${ }^{24}$

The point of examining von Humboldt's theory of knowledge is not simply to demonstrate the relevance of the archipelagic metaphor. It is to suggest that it grows from a particular geographical encounter. While von Humboldt's archipelagic conception of unity - shared incidentally with his brother - is presented as an epistemological desideratum, it has a provenance in the senses as well as the realm of inner contemplation. As early as 1807 Alexander had noted, 'The nearer we approach the tropics, the greater the increase in the variety of structure, grace of form, and mixture of colors, as also in perpetual youth and vigor of organic life'. In the sense the tropics provided the best real world laboratory in which to study the earth's physical history. The problem was that their mineral, vegetable and animal profusion threatened to overwhelm the senses. In South America Alexander was particularly impressed by the vertical stratification of ecosystems: 'The regions of the torrid zone not only give rise to the most powerful impressions by their organic richness and their abundant

\footnotetext{
${ }^{17}$ Ibid, 74

${ }^{18}$ Ibid, 76

${ }^{19}$ Ibid, 76

${ }^{20}$ Ibid, 88

${ }^{21}$ lbid, 82

22 lbid, 84

${ }^{23}$ lbid, 55.

${ }^{24}$ Ibid, 55
} 
fertility, but they likewise afford the inestimable advantage of revealing to man, by the uniformity of the variations of the atmosphere and the development of vital forces, and by the contrasts of climate and vegetation exhibited at different elevations, the invariability of the laws that regulate the course of the heavenly bodies reflected, as I were, in terrestrial phenomena.' ${ }^{25}$ This is the theory: that in the tropics 'organic richness' and 'the invariability of the laws' are both demonstrated to their maximum effect. In practice, though, as Jason Lindquist notes in his study of Alexander von Humboldt's Personal Narrative, the superabundance of tropical phenomena was overwhelming. Where 'lianas' climb from the ground to the treetops in a 'continual interlacing of parasite plants, the botanist is often led to confound the flowers, the fruits and leaves, which belong to different species. ${ }^{26}$ The lianas are natural 'connecting links' that not only confound the attempt to reduce the jungle to an aggregation of objects but suggest a vital principle indifferent and even hostile to rational species-by-species classification.

While Humboldt's assessment of tropical vegetation is invariably positive, he is conscious of 'entering in some sort on a new state of existence,' 'where man no longer appears as the centre of creation. ${ }^{27}$ For the observational scientist, the challenge is essentially discursive: 'It is now become scarcely possible to connect so many different materials with the narration of events,' a drama of 'dispersion and aggregation' which perhaps can only be resolved by adopting an archipelagic, rather than centralist or continentalist, compositional aesthetic. As Lindquist argues, the challenge of 'vegetable and visual overload' not only challenged Humboldt's 'aesthetic sensibility' and 'his ability to create a coherent textual representation of the New Continent: it stimulated 'significant epistemological shifts. ${ }^{28}$ In particular, it led Humboldt to regionalize phenomena, to attribute to the 'multitude of objects' to hand a 'peculiar character' that distinguished a 'zone' ${ }^{29}$; with this tool 'zones' could be differentiated but also compared and contrasted so that, gradually, broader organisational principles emerged. This was not only a powerful tool for understanding the physical history of the planet, it also suggested an aesthetic strategy. After all, European landscape artists were already used to grouping phenomena, subjecting the multitude of objects to picturesque compositional principles. The opportunity afforded by the tropics was to transform the picturesque into a heuristic device that could illuminate the principles of physical geography. For, if it was true that there is 'a certain physiognomy of nature exclusively peculiar to each portion of the earth,' then, in principle, 'the artist, by analyzing the various groups' might 'resolve beneath his touch the great enchantment of nature - if I may venture on so metaphorical an expression - as the written words of men are resolved into a few simple characters. ${ }^{30}$

But perhaps the expression was not metaphorical. To compare the discourse of physical geography to a painting by Claude Lorraine or Ruisdael was to emphasise the point that a philosophical understanding of the unity of the universe depended on holding all the parts in

\footnotetext{
${ }^{25}$ Ibid, 34

${ }^{26}$ Lindquist, 223

${ }^{27}$ Lindquist, Threats to the Human Subject, 223

${ }^{28}$ Ibid, 222

${ }^{29}$ Ibid 230

${ }^{30}$ Cosmos, II, 97. A 'physiognomical' study of this type by Albert Berg is illustrated in the Introduction to the Johns Hopkins University paperback edition of Cosmos (vol II, xviii): 'Such studies did not merely aim for picturesque effects ... in their ability to convey a physiognomy, they were also demonstrations of physical law and the "cooperation of forces".' (II, xix)
} 
play. It was an art of arrangement that disclosed the connecting links between parts, an irreducible and harmonious combination of many phenomena in such a way that they could be visualized and grasped all at once. To do this it had to exhibit a kind of chiaroscuro that suggested the intermingling of different phenomena: the centralized perspective technique of fifteenth century Florence would hardly do. The capacity of such landscape painters to harmonise the different elements depended on not looking too closely at individual elements. It involved a certain turning away or abstraction of vision from the particular. How else could the sublime, 'inexhaustible treasure' ${ }^{31}$ of the tropics be brought within the realm of computation? After all there was a paradox about von Humboldt's praise of the tropics: if it so promoted the advancement of learning, why was Europe the home of the sciences? Von Humboldt felt that a relationship existed between culture and climate - on which principle 'a land gladdened by cloudless azure skies' should encourage 'the natural capacities of the mind'; or, more particularly, a tropical environment should logically enjoy the highest intellectual development - 'As, therefore, richness and grace of language are unfolded from the most luxuriant depths of thought, so we have been been unwilling wholly to disregard the bond which so closely links together the physical with the sphere of the intellect. ${ }^{32}$ Why then has it been left to 'the inhabitants of a small section of the temperate zone' to discover the laws of nature? ${ }^{33}$

Von Humboldt finds this all the more surprising because the atmosphere in northern Europe, far from offering cloudless azure skies, is subject to 'perpetual local variations' that 'affect the movements of the atmosphere.' In short, it is cloudy. Perhaps the epistemological equivalent of this turbulent atmosphere is the concept of grouping: the natural chiaroscuro of the landscape provides the pattern or organizational template thrown over a multiplicity of phenomena. If that is the case, it took the encounter with the tropics to make it explicit. It was in the discovery of a zone that lacked chiaroscuro, where northern mists were absent and, instead, the sun beat down mercilessly and vertically on forests that only a naif artist - a rational Rousseau of the south - could hope to evoke, that the archipelagic 'atmosphere' of reason emerged. This did not mean, though, that such propensities would not be found in a far more advanced state in the tropics but they would, logically, be found not in the continental mountains and forests of South America but in the island-studded seas of the east. Accordingly, Alexander notes as a partial exception to the squandering of the advantages offered by these favoured [tropical] regions,' the advance of Sanskrit 'penetrating further within the torrid zone, as my brother Wilhelm von Humboldt has shown in his great work on the Kavi ..., 34

Von Humboldt's philosophy of science developed in response to the challenge of representing the tropics. His conceptualization of the cosmos depended on devising a geographical lexicon that was figurative, that made the strange familiar by making it possible to visualize it. In other words the tools he used 'to conquer cognitively the physical and historical world' were tropic: they were figurative forms of thought that had exact analogies in the theory and practice of language and in the history and aesthetics of western art. ${ }^{35}$ Because of this it was also logical that the second volume of Cosmos should be dedicated to an examination of the way poets, geographers, philosophers, painters and scientists had

\footnotetext{
${ }^{31}$ Cosmos, II, 93

${ }^{32}$ Cosmos I, 357-358.

${ }^{33}$ Cosmos 136

${ }^{34}$ Cosmos 1, 35, 36

${ }^{35}$ See on this F.R. Ankersmit's discussion of Hayden White's Tropics in History and Tropology: The Rose and Fall of Metaphore, 10.
} 
perceived and rationalized nature. The point made here is not simply that von Humboldt's method was tropological but that it derived from his encounter with the tropics. The trope or figure of speech renders the idea expressed more concretely by the term 'turn of phrase'. Tropic speech is a discourse of turning, of turning away and turning towards. The evasiveness of north European skies fosters a turning away from the sharp outline of particulars and a taste for generalized, composite forms (or regions). The same distance from phenomena, though, encourages a turning towards - a search for metaphors or other styles of figurative representation that bring what is obscure into clear view. If the external world available to us must mirror the constitution of the mind, then the turn that characterizes the formation of a concept is analogous to the galaxies 'agglomerated into rotating, revolving spheres.' Further, these spheres are not distributed at random but systematically - Humboldt speculated that the universe consisted of 'innumerable systems scattered like islands through the immensity of space, and each composed of a sun and a moon': in a further turn of speech, then, they can be thought of as island systems or archipelagos.

If an understanding of the cosmos depends on the order of language - what might be called a scientific tropology - it is in the study of language that a distinctively tropical knowledge might be expected emerge. Language stands between inner and outer worlds; it is the filter between the senses and the faculty of contemplation. Its template determines what can be grouped and linked in the external world and how these phenomena are ordered into concepts. Even if its writing is built out of very few characters, its discursive combinations are, like the organic richness of the tropics, inexhaustible. In non-Platonic reality, the richness and grace of language only unfolds from 'the most luxuriant depths of thought' because it also grows out of the most luxuriant depths of the tropics, the entanglement, that is, with those zones of the earth that because they 'give rise to the most powerful impressions by their organic richness and abundant fertility' also reveal 'the invariability of the laws that regulate the course of the heavenly bodies, reflected, as it were, in terrestrial phenomena. ${ }^{36}$ Here, incidentally, the tropological basis of Cosmos is stated: the dual study of heaven and earth is justified because each is a figure of the other. The community of thought is directly related to the community of nature - and indeed of other peoples who can be thought of like systems of stars or spiraling galaxies. Wilhelm von Humboldt explained, 'As the individual sound stands between the human being and the object, so the whole language steps in between him and the nature that affects him both inwardly and outwardly. He surrounds himself with a world of sounds, so as to take up and process within himself the world of objects. ... By the same act by means of which he spins language out of himself, he spins himself into it, and every language draws about the people that possess it a circle from which it is possible to exit only by stepping over at once into the circle of another., 37

To return to Wilhelm and to his championing of Kawi as a kind of Ursprache seems to be a return to the mythological mindset found in the search for Java's ancient pyramids, but one of the many distinctions of this von Humboldt's philosophical investigations is the light they throw on language as discourse. As already indicated, Wilhelm assumed that a multiplicity of languages had been spoken from the beginning. What mattered was not their putative origins but the dynamic manner of their development. Like his brother, Alexander, Wilhelm

\footnotetext{
${ }^{36}$ Cosmos I, 36

${ }^{37} 434 ; 60$

(academia.edu/1041855/The_Expressivist_Conception_of_Language_and_World_Humboldt_and_the_Charge _of_Linguistic_Idealism_and_Relativism)
} 
understood languages as heuristic tools for thinking the cosmos into being. It was the degree to which they actualized the complexity of phenomena and our relationship with them that interested him. Like the naturalist who only sees what is round him ${ }^{38}$ and yet intuits a regional physiognomy or character, so with the language speaker: while he is speaking to another person, he is also aware that this exchange presupposes a 'network' or community of speech: 'Language can be compared to an immense web, in which every part stands with the others, and all with the whole, in a more or less determinately recognizable context. Whatever his point of departure, the human being always makes contact in speaking with a merely selected part of this web, but does so always in such an instinct-like way, as if everything with which this one part must necessarily agree [in Übereinstimmungstehen muss] were simultaneously present to him in the same moment. 39

As discourse language is defined relationally and performatively. It communicates the shared interests of the speech community that uses it. Meaning always exists in-between people and the individual speakers find their place in the 'web' by the spin or original interpretation they place on the linguistic signs. Thus, Wilhelm explains, 'Nobody means by a word precisely and exactly what his neighbour does, and the difference, be it ever so small, vibrates, like a ripple in water, throughout the entire language. Thus all understanding is always at the same time a not-understanding, all concurrence in thought and feeling at the same time a divergence. The manner in which language is modified in every individual discloses, in contrast to its previously expounded power, a dominion of man over it. Its power may be regarded (if we wish to apply the term to mental forces) as a physiological efficacy; the dominion emanating from man is a purely dynamical one. In the influence exerted on him lies the regularity of language and its forms; in his own reaction, a principle of freedom. ${ }^{, 40}$ Obviously, and without straining the metaphor, this is an archipelagic conception of language as discourse. The 'ripple in water' corresponds to the creative region Cuevas-Hewitt promotes, 'the sea between - the site of multiple relationships that are never fixed, but constantly in flux.' The island/speakers in this achieve individuation or dominion over themselves because they internalize the rules of exchange across the archipelago. The spiritual freedom they enjoy is strictly analogous with the political freedom that Bas 'Umali describes - where a network of autonomous villages is possible because of the 'regularity' created by a regional 'archipelagic confederation.'

Turning to the case of Kawi and its related languages, it is not surprising, then, that W. von Humboldt associates its extraordinary development and dissemination with its archipelagic environment. The existence of a Malayan-Polynesian language culture reflects the 'stronger connection' that Malayans have with different cultures, due to the fact that 'They inhabit merely islands and archipelagoes, which are spread so far and wide, however, as to furnish irrefutable testimony of their early skills as navigators. ${ }^{41}$ The physical archipelago is a geographical analogue of language as discourse, as the to and fro of communication born of a necessity to relate across difference and distance. It is this archipelagic distribution of speech communities that, in his view, stimulates the growth of language. The archipelago is not a stable polyglot set of islands: it is an evolving interlingual discourse, where tongues are

\footnotetext{
${ }^{38}$ Lindquist quotes Humboldt to the effect that the proper subject of a travel narrative is the 'man himself ... in contact with the objects that surround him.' (230)

${ }^{39} 434: 60$

${ }^{40}$ www.marxists.org/reference/subject/philosophy/works/ge/vhumboldt-wilhelm.htm

41 See Mirak-Weissbach, 'Wilhelm non Humboldt and the study of the Kawi Language,' EIR Volume 25, Number 46, November 20, 1998
} 
constantly morphing, innovating and migrating. The key point here is languages will be favoured that relate easily, which travel. Good travelling means in this context having a formal or intellectual impulse that lends them a sense of direction (or self-regulation) and a freedom to self-modify.

The grammatical expression of this evolutionary potential and situational flexibility was accidence, that part of language that allows the self-modification of words to express speaking positions. 'The inflectional method in its total perfection ... alone provides the true, inner firmness for the word with regard to the intellect and the ear, and at the same time distinguish[es] securely the parts of the sentence in accordance with the necessary intertwining of thoughts, ${ }^{42}$ It is this combination of firmness and flexibility that allows highly inflected languages to plumb 'the most luxuriant depths of thought.' At the same time a perfected accidence optimizes the scope for communication with others: 'Since it takes each element of speech in its twofold value, in its objective meaning and its subjective relationship to the thought and language, and designates this double relationship in its proportional weight through forms of sound designed for the purpose, it increases the most original essence of speech, articulation and symbolization, to its highest grades. ${ }^{43}$ It is the double endowment of accidence, its capacity to facilitate the inner (the mental unfolding of the relationship between ideas) and the outer (the articulation of speaking positions) that leads von Humboldt to characterize a perfected accidence with 'a pure principle in lawful freedom.'

Kawi, then, meets Von Humboldt's beau ideal of language because of its sophisticated accidence; but, on the principle that cultures retain a trace of the geographical region where they grow, it is more than an accident that Malayan-Polynesian language culture has an archipelagic provenance and distribution. A capacity to mark speaking positions, to differentiate different temporal states and degrees of probability, would obviously be critical to building a consensus when peoples from different places met and attempted to find common ground. The affixes and suffixes that signified self and other, singular and plural, subject and object, agency, ownership of the past and design on the future were the hinges of sociability that enabled language to create a common place where differences could be discursively inscribed and regulated. Humboldt's advocacy of inflection as a sign of 'lawful freedom' is sometimes held to indicate racism (notably because of his review of Chinese) but perhaps it expresses an archipelagic conception of languages, in contrast to the continental or self-contained model of communication and culture represented by an imperial power. ${ }^{44}$ In this case the bias is political rather than racial: Chinese is perfect in its own way but its mode of representing logical operations, its uninflected but self-consistent grammar, seems to make the evolution of thought and the progressive emancipation of minds impossible: 'Operating perfectly without inflection, Chinese is no longer considered to have a deficient structure; but the inflecting languages are, in his eyes, characterized by a heuristic surplus that results from the repercussions of the formal-phonetic aspect on the mind. ${ }^{45}$ Meissling explains the nature of the surplus as follows: 'Over and above the fact of rendering the idea of a specific activity, the inflecting verb embraces the person, modality and time, activity or passivity without

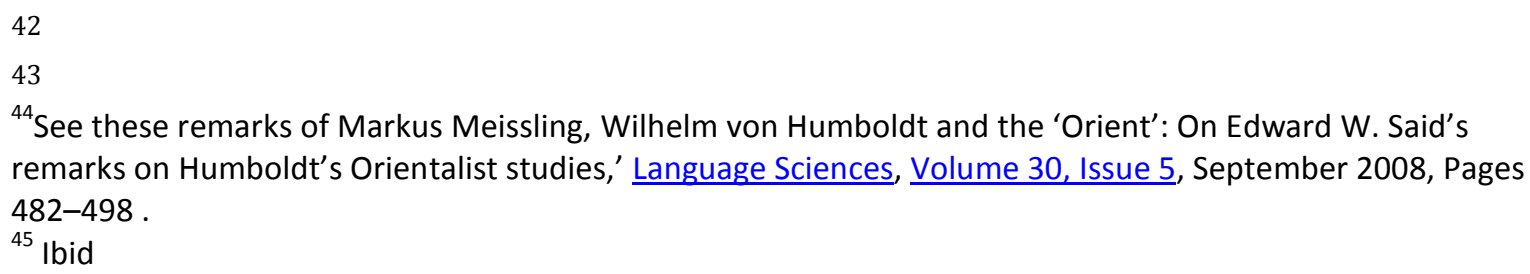


recurring to a compilation of different conceptions. It simultaneously expresses all the features of an existing entity. ${ }^{46}$ In other words, it encourages the language participant to understand the speech act performatively, as an act of 'intellectual development." ${ }^{47}$

The parallel between Wilhelm's discursive definition of languages and Alexander's theory of knowledge becomes clearer when their shared interest in defining the relationships between phenomena are considered. The key to organizing the 'aggregation' of facts into significant groupings lay in the discovery of 'connecting links', those conceptual lianas that joined separate species, even obscuring their particularities in order to reveal a larger order or physiognomy. In the same way it has been argued that 'Humboldt's critique and transposition of signification-as-representation [illustrated by the phenomenon of grammatical accidence] into language-as-thought serves to illustrate the critical importance of an originary zone of indistinction operating between various languages.' Like Alexander's torrid zone, such a zone optimises creative potential, the proliferation of new forms organic and intellectual. Like the sea between of the archipelago which accommodates an infinity of routes, encounters and exchanges, 'this immanent zone has an obscure, but critical function - the production of transcendental field where thought and language co-exist completely intersecting here, diverging there, assembling and re-assembling one another upon an infinite virtual plane.' The methodological corollary of this view is that no language or region of discourse can exist without another (and this is true down to the scale of the individual speaker's relationship with their interlocutor) and that, consequently, just as Alexander's vision of unity must co-exist (and be mediated through) inexhaustible variety, so the 'structural genesis and operative functionality' of Wilhelm's prototypes ('both a set of finite rules as well as a series of constructive procedures') 'cannot be discovered except by empirical investigation of language use in many different languages with widely divergent structures. $^{48}$

Considered as a discourse, the cosmos will speak most truthfully about itself where the connections are most easily observed. This may sound like a truism; in fact, it implies an archipelagic distribution of matter. The scientific observer who discovered the biological principles corresponding to Wilhelm's theory of Kawi was, of course Alfred Russel Wallace. The 'Malay archipelago' favoured the discovery of 'development' - a tropical exfoliation of species and types - because it possessed a near infinity of coastlines, linear zones that at once separated island from island and offered a landing place or site of re-assembly. The relationship between its fertility of invention and its anti-continental nature was captured by Wallace when he wrote: 'The absolute extent of land in the Archipelago is not greater than that contained by Western Europe from Hungary to Spain; but, owing to the manner in which the land is broken up and divided, the variety of its productions is rather in proportion to the immense surface over which the islands are spread, than to the quantity of land which they contain. ${ }^{49}$ But it is not simply the extent of the surface. If the islands were too thinly spread, in a hyper-sporadic way, communication between them would be attenuated not intensified. It is the optimal relationship of coastlines to sea between that creates opportunities for transfer and transformation - that fact that islands or landing places can be seen in all directions. With this important topological proviso, in the development of thought, in the

\footnotetext{
${ }^{46} \mathrm{Ibid}$

47 Ibid

${ }^{48}$ fractalontology.wordpress.com/2008/01/28/language-is-not-a-signal-notes-on-wilhelm-vonhumboldt/

${ }^{49}$ Wallace, The Malay Archipelago,
} 
development of progressive political systems - and in the development of biological diversity and complexity - the 'sea between' is everything. It is the immanent zone where new ideas, new laws and new species can, and perhaps must, come into being.

The archipelago provided both Darwin and Wallace with a regional case study for the apparent phenomenon of zoological regions: in the formation of the archipelago could be reconstructed the formation of biogeographical regions. As Jane Camerini notes, 'From an evolutionary point of view, a naturalist would not expect an archipelago of physically similar islands to be populated with strikingly different animals on its western and eastern ends. ${ }^{50}$ To explain the striking contrast between the biota either side of what became known as the Wallace Line, the naturalist, without the advantage of tectonic plate theory imagined, that the Malay archipelago was the result of submarine volcanic activity which, over time, had thrown up between the great continents of Australia and Asia 'an irregular archipelago of islands. ${ }^{51}$ Supposing that these islands "would sometimes become connected with the land on one side or other of the strait, and at other times again be separated from it, ${ }^{52}$ the migrations of animals outwards from either continent might lead to the situation observed between Bali and Lombok where despite their close proximity, the islands exhibited 'an almost unmixed sample of the productions of the continents of which they had directly or indirectly once formed a part. ${ }^{53}$ But, whatever the correct geological theory was, the salient point was that the evolution of the archipelago and the evolution of species went together. And this was true even without Wallace's brilliant theorizing. As Charles Darwin had speculated in Notebook B from 1837: 'Species formed by subsidence. Java \& Sumatra. Rhinoceros. Elevate \& join keep distinct. Two species made. ${ }^{54}$ Forces of disaggregation and re-aggregation provided the longterm environmental changes hypothesized as necessary for the transformation of species into new species - and for their continuing distinctness in the event of later sympatry. The essential environmental mechanism in this scenario was the archipelago.

A feature of tropic theory is the significance it gives to analogies between large and small. In a pre-fractal way it sees self-same patterns repeating themselves at different scales. Humboldt values the tropics not only because they exceed calculation - and therefore stimulate the mind to advance knowledge, regionalizing, grouping and discerning immanent lines of development - but because they bring him closest to the stars. The richness of one is reflected in the richness of the other: 'There the depths of the earth and the vaults of heaven display all the richness of their forms and the variety of their phenomena. ${ }^{55}$ His physical geography is, in this sense, also a poetic geography, an art and science of analogy, or tropology, that discerns patterns, or forces of self-organisation operative at different scales. Like Wallace after him, Humboldt is equally interested in the geographical distribution of humans; both held progressive political views. Wallace, in particular, as an advocate of Land Nationalisation, imagined a future England where the redistribution of land would create a new smallholder class, organized presumably in a way resembling Umali's archipelagic confederation. The archipelago is not, then, a metaphor so much as a model or prototype for

\footnotetext{
50 Jane R. Camerini, 'Evolution, Biogeography, and Maps: An Early History of Wallace's Line, 709

${ }^{51}$ The Malay Archipelago, 28

52 Ibid

53 The Malay Archipelago, 29. Camerini notes the influence of von Humboldt on the emerging interest in the geographical distribution of animals and plants and the emergence of regionalisation a a key concept in protoevolutionary theory. (706)

${ }^{54}$ Quoted by Camerini (712) who discusses the corollary of this speculation, 'the distribution of animals with relation to soundings.' (717)

55 Cosmos 1, 33
} 
conceptualizing complexity, for ordering a universe without reducing it to sterile axioms and generalisations. Its methodological value is to accommodate the 'immense surface', the 'sea between' and, more precisely, the arrangement of islands throughout these. Its form maps communication: without the multiplicity of contacts it demands, discourse would have no need to exist. The clarification of relationships, though, the discovery of the rules governing social intercourse across difference, depends on locating the coastlines, those relative standpoints where the labyrinth of the archipelago, and the desire of exploration it induces, can be contemplated most acutely.

Oddly, one can see a refraction of this relationship between spatial organization and the investigation of complexity at a more intimate scale in Wallace's collecting methods. Wallace paid for his seven years labour in the Malay Archipelago by collecting animals for London collections. His much praised narrative is a also a chilling catalogue of slaughter: the empathetic lobotomy of a man in other respects so alive to the needs of his fellow sentient creatures deserves an important place in the literature of imperial desensitization. Be that as it may, like Humboldt, Wallace found the tropical islands of the Indonesian archipelago strictly impenetrable. He was therefore dependent on earlier European intrusions for access. The tracks opened up for industrial purposes provided him with the coastlines, the openings out of the jungle that allowed it to be reached, raided and read. Such pathways began the process of turning a continent of country into an archipelago of forest stands. 'There are certain requisites of a good collecting-ground,' Wallace writes apropos of the island of Batchian: 'In some places there is no virgin forest, as at Djilolo and Sahoe; in others there are no open pathways or clearings, as here. At Batchian there are only two tolerable collecting-places, the road to the coal-mines, and the new clearings made by the Tomore people. ${ }^{56}$ In Dore Wallace's efforts to track down birds of paradise were ineffectual until sailors from a visiting Dutch vessel, in cutting down large trees to make firewood to fuel their steamer, "cleared a number of wide, straight paths through the forest in various directions, greatly to the astonishment of the natives, who could not make out what it all meant." Not so Wallace who understood immediately the opportunity offered him: "I now had a variety of walks, and a good deal of dead wood on which to search for insects."

These coastlines had their counterpart in the organization of the narrative. Like Humboldt in the South American tropics, entering the archipelago Wallace felt himself decentred, in danger of being intellectually overwhelmed: 'I have found it impossible to give such an account as I desire of the natural history of the numerous islands and groups of islands in the Archipelago, without constant reference to these generalizations ... ${ }^{58}$ By this he meant his bio-geographical regionalization of the archipelago - which was not only a scientific hypothesis but a discursive strategy, one that ultimately led to the re-continentalisation of the archipelago. For, as he stressed, his fivefold division of the Malay Archipelago (the IndoMalay Islands (Malay Peninsula, Singapore, Borneo, Java and Sumatra), the Timor Group (Timor, Flores, Sumbawa and Lombok), the Celebes Group (Sulawesi and Buton), the Moluccan Group (Buru, Seram, Bacan, Halmahera, Ternate, Tidore, Makian, Kayoa, Ambon, Banda, Gorong and Watubela), and the Papuan Group (New Guinea, Aru, Misool, Salawati and Waigeo) not only aimed at narrative clarity (in fact, Wallace said that he hated 'writing narrative') but at intellectual interest. 'I want something to argue on,' he explained.

\footnotetext{
${ }^{56}$ The Malay Archipelago, 346

${ }^{57}$ Ibid. There are many comments of this kind scattered through the book.

58 Ibid, 29-30
} 
Arranging his diaries geographically, rather than chronologically, Wallace introduced the bio-geographical hypothesis, which, in advance as it were, lent the organic richness and abundant fertility he had to describe a regulatory and purposeful framework. Having acknowledged the spread of the archipelago, Wallace saw it as his task to pull it back together, to draw rings around various 'groups' of islands so that their inexhaustible variety could be visualized and rationalized and the reader, unlike the naturalist, could walk a reasonably straight path through virgin territory. The effect of this is to continentalise an archipelagic experience as the persuasiveness of his argument depended on the prior decision to arrange the zone of his exploration into groups of islands, and the consequent segmentation and sedimentary layering of each section of text. Wallace visited the island of Timor three times, briefly staying at Coupang in 1857, returning there for two weeks in May 1859 and finally spending four months at Delli in spring 1861. In The Malay Archipelago a synthetic account, combining data from all three visits, is presented, and the chapter where this appears is followed immediately by another providing an overview of the natural history of the Timor Group. Wallace folds together his journals, three chronologically distinct periods or pages are superimposed one on the other because of their reference to the same topos (place) - and by this segmentation and sedimentation a new topos (topic) comes into clearer relief - Timor, no longer simply an island but a rhetorically outstanding step in Wallace's argument.

The evolutionary linearism imposed on the historical record cancels out at every step the spatial history of the fieldwork, with its systole and diastole pattern of repeated passes across seas, ports and coasts, its zigzag of first impressions, misidentifications, reversals and revisions out of which Wallace's own ideas developed. But an interesting consequence of this immense scientific synthesis, through which the spread of the archipelago is reduced to a group of provinces structurally subordinated to a single principle of biogeographical evolution, is that the very clarity of its organization enables to Wallace to infill, as it were, his bare design with a good deal of picturesque narrative detail. Wallace confessed to feeling dreadfully 'the want of copious notes on common everyday objects, sights and sounds and incidents, which I imagined I could never forget but which I now find it impossible to recall with any accuracy,' but in revising his field journals he did everything possible to improve their local colouring, their vivacity of detail and narrative interest. Having cleared a path through the jungle of the data, he is able to plant the text with gardens of descriptive luxuriance that bring the adventure of exploration to life. Again, the garden is not simply a metaphor, or decorative addition: it is the state of higher organization - intellectual enclosure and display - that the whole scientific enterprise drives towards. With typical subtlety Humboldt quibbled: in describing the 'vaporous matter of the immeasurable regions of space,' he would he said have borrowed a Greek phrase which, translated, means 'garden of the universe.' What prevented him from doing this was the association of 'garden' with enclosure - when, presumably the flowering stars stretch like Wordworth's daffodils to the edge of the senses and beyond.

Even so, a garden is the thing: it is the region represented as a map. An astronomer like William Herschel, who 'broke through the inclosures of heaven,' was 'like another Columbus [who] penetrated into an unknown ocean, from which he beheld coasts and groups of islands, whose true position it remains for future ages to determine. ${ }^{59}$ To map the islands so that their archipelagic constitution could be discerned was the same as mastering the flowering heavens. The old 'inclosures' would be swept away and new templates of organization thrown over the data: the intellectual cultivation of nature would produce new gardens of the

${ }^{59}$ Cosmos, 1,87 
mind, systems of classification able to map the true positions and relations of phenomena. In which case, the question becomes: could an archipelagic epistemology survive this reduction - and, given the geo-political applications of archipelagic thinking that have hovered along the borders of this essay, could an archipelagic way of thinking produce at a regional scale a new approach to the governance of the excess - characteristic both of the tropics and of tropological thinking? In his footnote on the etymology of Cosmos, von Humboldt goes on to speculate about the meaning of world, ending with: 'the word appears to have signified among the Goths the terrestrial surface girded by seas (marei, meri), the merigard, literally garden of seas. ${ }^{60}$ What would that phrase signify in contemporary thinking about the environment? How would an inversion of the continentalist hierarchy, in which the islands (and lands) were placed in the position formerly occupied by the sea, effect theories and practices of regional organization and governance?

Perhaps a new kind of 'worlding' would be possible. If so it could learn from Californian cultural studies scholar Rob Wilson's 'worlding' project. Worlding, in Wilson's conception of it, involves 'a kind of trans-critical process of listening to and caring for one's own lifeworld as well as the related and emergent species of others... ${ }^{61}$ : Against the domineering process of neo-liberal globalisation at home and abroad [...] critical processes and poetic tactics of worlding, as we urge, building up a life world palpably disclosing its lived-in modalities, boundaries, tactics, and historical processes of humanities survival and being-asdwelling [...] we become capable of letting the thing become present and near (located)... ${ }^{, 62}$ The practice of care advocated here stands in strong contrast to the 'hands off' genealogy of western thinking - exemplified respectively by von Humboldt's contemplative Olympianism and Wallace's easy identification of taxonomy with taxidermy. But in order to adapt it to the archipelago, it would be necessary to multiply his regions of care and to cultivate care at a distance. This would not be impossible under Wilson's scheme as he understands regions immanently, as what humans produce when they care about the world. Heidegger, who stands behind his argument, points the way, Wilson says, out of this (global) predicament of carelessness associated with displacement "by disclosing and activating a process of "being thrown (Geworfenheit) into the world," [being] never fully at home in it, always dislocated, "out of joint" as a constitutive condition of lack, social formation, a symbolic-ideological contestation.' It is a formulation that recalls in many ways Wilhelm's concept of discourse, as a negotiation of self-other relations characterized by constant semantic contestation and symbolic expansion.

Identity in these formulations is redefined in terms of identifications. In this case the scatter of the archipelago figures forth Wilson's image of being thrown into the world; for it is not only the individual who is thrown into the world but the world - for, as Humboldt's physical geography of the Darwin/Wallace theory of regionally-related evolution show, the world itself is also in a state of becoming, of formation and contestation. In this archipelago is the first 'garden' of the organizing mind that allows this systole-diastole patterning of reality to be mapped and lent human meaning. Jean-Luc Nancy advances an archipelagic concept of community when he reconfigures the triad necessity (being), possibility (theory) and reality (practice), arguing that 'the politics of linkage [] does not privilege the real either as that on which practice should act or as the action of practice ... Between the reality of any fixed community and the possibility of a free subjectivity, the "act of trying" is always neither

\footnotetext{
${ }^{60} \mathrm{Ibid}, 70$ footnote

${ }^{61}$ Rob Wilson, The Worlding Project: Doing Cultural Studies in the Era of Globalisation (Santa Cruz: New Pacific Press, 2007), 213.

${ }^{62}$ Ibid., 216.
} 
possible nor real, neither active nor passive. Like a decision, it remains to be repeated in order to have occurred. And what it acts upon is unities that are other knots in turn (i.e. other knottings (neither simply possible nor simply real) in the process of being tied up and coming untied, and with which it - passively also - finds itself tied up). ${ }^{63}$ Nancy's idea of knots recalls Descartes' vertical theory of the organization of the heavens. It is also reminiscent of Wilhelm von Humboldt's notion of the individual spinning himself into and out of language.

But perhaps a capacity to live in the linkages, along the coastlines of identification, is the way identity is ordinarily worked out in the archipelago. According to Vanja Hamzic, 'the world's largest archipelagic state' (Indonesia) exhibits a distinct 'cultural and spiritual plurality' ${ }^{64}$ 'The turbulent tides of trading, migration and warfare have raged along their shores for centuries, moulding syncretic ethnoscapes, wherein an islandic self is dynamically negotiated between the allegiance to local narratives and the need to adjust to foreign winds, be they of Indic, Arab, colonial European or some other more or less distant origin. ${ }^{65}$ Here, again, a tropical politics is indicated. That is, literally and figuratively, a habitual turning towards and away from the other. The imperial tour is replaced by the postcolonial detour. Instead of a new neo-nationalism - a fresh attempt to subordinate the archipelago to nationalist selfinterests - a distributed self-government is advocated. This project is forcefully identified by Edouard Glissant: 'Archipelagic thinking flows along with the course of our worlds. It borrows from their ambiguity, fragility, and derivativeness. It accepts the practice of detour, which is neither escape nor renouncement ... Is it to renounce self-government? No, it is to accord with that which, from the world, has diffused into the archipelagos precisely, the diversities in expanse, which nevertheless gather the shores and marry the horizons.'

But how is this to be translated into political, social and cultural praxis? How is the 'worlding' of the archipelago to be translated into a movement that might produce new approaches to the governance of the diffused as such? One finding of this essay is that a Humanities worthy of its name changes its character when it pursues tropical knowledge; for in the tropics one cannot divorce observation from production - this is the necessity under which any tropical discourse labours, to confront the ethical and aesthetic responsibilities involved in reducing the infinite to what can be conceived and manipulated. Glissant continues, 'We recognize that which existed in the continental, in its thickness, and which weighed heavily on us in the sumptuous thinking of the system that until today controlled the History of humanities; and that they are no longer adequate to our explosions, neither to our history nor to our no less sumptuous wonderings. Archipelagic thinking, based upon archipelagos, opens these seas to us. ${ }^{66}$ The new humanities will need to be transdiciplinary in Wilson's sense but also productive. It will need to locate itself conceptually on the coast and to understand the coast differently, not simply as a metaphor of connectedness but as an amphibious zone that, at a that smaller scale, is also constituted and inhabited archipelagically.

The difference of archipelagic consciousness in the practice of coastal communities in the archipelago is that their self-understanding is environmentally grounded. Picking up on the ontological implications of living by the sea - or, as John Havea puts it, living as people ' $\mathrm{f} / \mathrm{f}$ the boundary,' Nancy Victorin-Vangurud remarks: 'An archipelagic imagination seeks fluid

\footnotetext{
63 Jeffrey S. Librett, 'Between Meaning and Power' in Ibid, 124-125

64158

65 Ibid

66
} 
boundaries without reducing any one subject to "the Same". The image opens up a horizon where one's identity is constituted in and through the communal, even cosmological ontology of "interbeing", where people remain responsive and accountable to each other, other beings, the land and the sea. ${ }^{67}$ Whatever the typology, 'In an archipelago the water between islands is typically called a channel or passage ...' But, as I have indicated, passage, the sea between, is not simply a geographical concept, it is a way of organizing concepts differently. The nation-state, for example, finds itself vulnerable to an eco-poetics of the edge, to a reevaluation of fluidity. To return to our region, Lanani Marika of north-east Arnhem Land explains, 'We sing from the shore to where the clouds rise on the horizon,' adding 'this is why we always have to live here. So that we can see the water going out and coming in ...' The Tjerri or Sea Breeze Dreaming (ngirrwat) has a site and 'Both humans and non-human phenomena born of these sites are seen as incarnations of the ngirrwat. ${ }^{68}$ Similarly, again, in Yolngu culture we are told that 'The perceptions of water are fluid and ambiguous depending on context and a person's ancestral affiliation reflecting the many faces of those looking at it. ${ }^{69}$

As Marcia Langton writes in another context, 'Along with other features of the natural world, the estuarine zone is not just a bio-physical feature, but a metaphorical reference to knowledge. ${ }^{70}$ Place as passage, self as other or spirit double, orientation as authority and responsibility: these are perceptions of place integral to life in the archipelago. Such an awareness has implications for regional governance, a proposition that forms the subject of 'Ocean Connections', an archipelagic conversation beginning in northern Australia and seeking to engage like-minded, predominantly coastal communities around and across the Arafura and Timor seas. This is not the place to enlarge on it here, except to note that it seeks to mobilise a tropical knowledge or way of knowing the world, one that understands the role of the humanities in producing care at a distance as simultaneously ethical, aesthetic and performative. It is not the kind of project likely to attract national funding, for obvious reasons. It is not even a project, rather a self organizing region of conversations and actions aimed at mapping an archipelagic discourse about local knowledges and their linkages. It will be a process of simultaneous assembly and detour, and its graphical representation over time would like something like a picture of turbulent flow, an evolving system of vortices.

But perhaps the most radical turning about envisaged here for the governance of excess is already found in Indigenous ontologies. It is a description of the world that acknowledges the fact that it is turning. Yardaman elder Bill Yidumduma Harney's description of the turning universe perceived in the slow rotation of the stars suggests as much. According to him, he space between sky and earth is not a third entity: it is the sky and earth considered as a composite movement form, an 'up-and down'. Harney compares this inter-relational domain to the way 'The spider web can fly. ${ }^{, 71}$ When it flies, it remains anchored to the spider who lets out the thread. In a way, someone walking at night is let out by the stars - 'Everything becomes a star in the night ... Human become a star called Milijurn. They come down from sky to ground. If you wake up at 1 o'clock in the night or 2 o'clock, you just lay down and just watch them. You see all the stars all dancing! ${ }^{72}$ The allusion is not simply to their punctiform scintillation but to the impression that the heavens are turning - 'Planets making

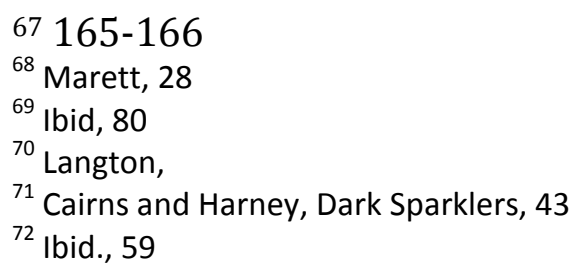


the pathway! Travelling routes, a pathway you could call it, like a highway. ${ }^{73}$ Anyone travelling at night is held in this moving web, they negotiate a labyrinth that comes with them. This sense of being held in the hollow of a cosmic hand is proof against becoming lost. To understand this philosophy of ambience, it is necessary to reconnect discourse to the sites of its physical production, in this case to think breath, voice, echo, manner of speaking and gesture together with their environmental counterparts, wind, cave, constellation and cloud.

Here, then, the poetic logic of von Humboldt's Cosmos turns, as it were a complete circle. The turn towards the tropics was necessary because the scientist who sought to retain a sovereign stillness could not hope to encounter, study and make sense of nature's inexhaustible variety (best studied in the tropics). Once there, enchanted and uplifted, the romantic scientist had the impression that heaven and earth were poetically (and perhaps scientifically) governed by the same organizing principles. If these could be found the outcome would be the stilling of the eternal rotations and counter-rotations; and the tropical scientist would, by the detour of tropological thinking, come back to the terra firma of a physical history and geography of the universe that identified and stabilized the metamorphoses of the universe. What this grand return to order omitted was the obvious fact, lent ontological significance in Bill Yidumduma's philosophy, that we also are turning; our observations are rotatory and the phenomena around us also revolve. This is a conception of care that spreads out into the distance, of a universe archipelagic in every direction, whose excess is nevertheless under the jurisdiction of care at a distance.

73 Ibid., 64 notes 